\title{
Effects of Hippophae rhamnoides extract on oxidative mucosal injury induced by cisplatin in rat jejunum.
}

\author{
Aynur Arslan', Fatih Ozcicek², Ferda Keskin Cimen ${ }^{3}$, Hatice Sevim Nalkiran ${ }^{4}$, Mine Gulaboglu $^{5}$, Nihal \\ Cetin $^{6 *}$, Taha Abdulkadir Coban ${ }^{7}$, Mehmet Kuzucu ${ }^{8}$ \\ ${ }^{1}$ Department of Internal Medicine, Istinye State Hospital, 34465, Istanbul, Turkey \\ ${ }^{2}$ Department of Internal Medicine, Faculty of Medicine, Erzincan University, 24030, Erzincan, Turkey \\ ${ }^{3}$ Department of Pathology, Faculty of Medicine, Erzincan University, 24030, Erzincan, Turkey \\ ${ }^{4}$ Department of Medical Biology, Faculty of Medicine, Recep Tayyip Erdogan University, 53100, Rize, Turkey \\ ${ }^{5}$ Department of Biochemistry, Faculty of Pharmacy, Ataturk University, 25000, Erzurum, Turkey \\ ${ }^{6}$ Department of Pharmacology, Faculty of Medicine, Selcuk University, 42131, Konya, Turkey \\ ${ }^{7}$ Department of Biochemistry, Faculty of Medicine, Erzincan University, 24030, Erzincan, Turkey \\ ${ }^{8}$ Department of Biology, Faculty of Science and Letters, Erzincan University, 24030, Erzincan, Turkey
}

\begin{abstract}
Objectives: We aimed to assess the effect of Hippophae rhamnoides extract (HR) on oxidative stress induced by cisplatin ( $\mathrm{Cis}$ ) in rat small intestine tissue by evaluating the biochemical and gene expression levels and histopathological changes.

Materials and methods: The control group and Cis group received distilled water, while the HR25+cisplatin (HR25+Cis) group and the HR50+cisplatin (HR50+Cis) group were given HR 25 and 50 $\mathrm{mg} / \mathrm{kg}$, respectively, orally for seven days. HR25+Cis, HR50+Cis, Cis groups were injected with a single dose of intraperitoneal cisplatin on the first day. After sacrifice, the jejunum of each rat was removed for the assessment of oxidants and antioxidants. Analyses of the gene expression (for IL-1B and TNF- $\alpha$ ) and histopathological changes evaluated.

Results: HR significantly inhibited the increase of oxidants and the decrease of antioxidants caused by cisplatin in the jejunal tissue. IL-1 $\beta$ and TNF- $\alpha$ gene expression levels were almost the same in both the HR50+Cis and the control groups. HR better prevented increase of the serum levels of IL-1 $\beta$ and TNF- $\alpha$ in animals at $50 \mathrm{mg} / \mathrm{kg}$ dose compared to $25 \mathrm{mg} / \mathrm{kg}$ dose. We confirmed that HR prevented the histopathological changes caused by cisplatin.

Conclusions: It was concluded that oxidative stress caused by cisplatin may be preventable by coadministered HR.
\end{abstract}

Keywords: Cisplatin, Hippophae rhamnoides, Oxidative stress, Rats, Small intestine.

Accepted on November 01, 2017

\section{Introduction}

Cisplatin is a broad-spectrum, non-period specific, platinumderived chemotherapeutic drug used in the treatment of various solid cancers [1]. Serious side effects encountered during chemotherapy limit the use of cancer drugs in many patients [2]. When seen during chemotherapy, mucositis has an important dose-limiting toxicity in the treatment of malignant diseases [3]. Free oxygen radical formation via reactive oxygen species (ROS) and DNA damage are observed in the initial stage of pathobiology of mucositis development. Then, endothelial epithelial cells release proinflammatory cytokines such as tumor necrotizing factor- $\alpha$ (TNF- $\alpha)$ and interleukin- $1 \beta$ (IL-1 $\beta$ ) [4-6]. Eventually, tissue damage and ulceration develop, and the mucosa becomes prone to bacterial contamination [7]. In a study by Bodiga et al. cisplatin was reported to produce damage via oxidative stress in rat ileal tissue [8]. Based on this information from the literature, it is thought that drugs that have a combination of antioxidant, antiulcer, antitoxic and antimicrobial activities might be beneficial for the treatment of cisplatin-induced ileal toxicity. However, there is still no standard approach for the prevention and treatment of mucositis. Although palliative measures, mucosa protectives, topical antimicrobials, ice, and analgesics 
are commonly prescribed, none of these methods is effective [9]. Therefore, research into preventing the toxicity of cisplatin on the intestinal tissue continues. Hippophae rhamnoides extract (HR) has been demonstrated to have antioxidant, antiulcerogenic, radio protective, antitoxic and antimicrobial effects $[10,11]$; in this study, we examined the outcome of HR against cisplatin-induced ileum mucositis.

HR is obtained from the fruits of the Hippophae rhamnoides $\mathrm{L}$ plant, which is a member of the family Elaeagnaceae and contains carotenoids $(\alpha, \beta, \gamma)$, riboflavin, vitamin $\mathrm{C}$, tocopherol, tocotrienol, folic acid, linoleic acid, $\alpha$-linolenic acid, palmitoleic acid and tannin [12-14]. This suggests that HR may be more beneficial than antioxidants and vitamins used alone for the treatment of cisplatin toxicity. In addition, HR has been reported to protect the gastric tissue from oxidative damage during the administration of indomethacin and methotrexate [15]. No previous study that investigated the protective effects of HR against cisplatin-induced jejunum mucositis was found in the literature. Therefore, in this study, we aimed to investigate the effects of HR against experimentally induced mucositis following the use of cisplatin in rats. The relevant biochemical parameters, gene expressions, and histopathological changes were also evaluated.

\section{Materials and Methods}

\section{Animals}

A total 24 albino Wistar male rats weighing between 200 and $220 \mathrm{~g}$ were randomly selected. Before the experiment, rats were divided into 4 groups with 6 rats in each group and the animals were housed and fed in the pharmacology laboratory at room temperature $\left(22^{\circ} \mathrm{C}\right)$. Animal experiments were performed in accordance with the National Guidelines for the Use and Care of Laboratory Animals and were approved by the local animal ethics committee of Recep Tayyip Erdogan University, Rize, Turkey (Ethics Committee Number 2015/34, dated 04/ 27/ 2015).

\section{Chemical agents}

Cisplatin CDDP vials (50 mg/100 mL; Cisplatin-Ebewe) were provided by Liba-Turkey. Thiopental sodium (Pental sodium) was purchased from I.E. Ulagay Turkey, and the Hippophae rhamnoides extract was provided by Karen Bilim-Turkey.

\section{Experimental groups}

The experimental animals were divided into control, HR25 + cisplatin (HR25+Cis), HR50 + cisplatin (HR50+Cis), and cisplatin (Cis) groups.

\section{Experimental procedure}

HR 25 and $50 \mathrm{mg} / \mathrm{kg}$ were administered to the HR25+Cis and HR50+Cis groups, respectively, and distilled water was used as the solvent in the Cis and control groups for the oral gavage. $\mathrm{HR}$ at a dose of $50 \mathrm{mg} / \mathrm{kg}$ has been reported to better prevent the oxidative tissue damage induced by anticancer drugs [15].
One hour after the HR and distilled water administration, the $\mathrm{HR} 25+\mathrm{Cis}, \mathrm{HR} 50+\mathrm{Cis}$, and Cis rat groups were injected with a single dose of $6 \mathrm{mg} / \mathrm{kg}$ cisplatin intraperitoneally. This method can lead to oxidative damage in the intestine of the rats [16]. HR and distilled water were given once a day for seven days, and the status of the rats was followed every day. At the end of this period, all the rats were sacrificed with a high dose of thiopental sodium anesthesia and the small intestines (jejunum) were removed. Following the macroscopic evaluation of the jejunal tissues, malondialdehyde (MDA), nitric oxide (NO), total glutathione (tGSH), glutathione s-transferase (GST), glutathione peroxidase (GPO), and catalase (CAT) levels were determined in the biochemistry laboratory. IL- $1 \beta$ and TNF- $\alpha$ gene expressions were measured in the jejunal tissue and serum. In addition, the jejunal tissues were histopathologically evaluated. The results obtained from the Cis group were evaluated in comparison with the results produced by the HR25+Cis, HR50+Cis, and control groups.

\section{Biochemical analysis}

Preparing the samples: Each $25 \mathrm{mg}$ of tissue was homogenized using a solution of $1.15 \%$ potassium chloride (KCl) (Merck, Germany). The homogenates were centrifuged at $4000 \mathrm{rpm}$ for $30 \mathrm{~min}$ at $4^{\circ} \mathrm{C}$. The supernatants were then used for the biochemical measurements. The $25 \mathrm{mg}$ tissue sections taken for tGSH analysis were washed with isotonic sodium chloride (I.E. Ulagay, Turkey) and subsequently brought to a total volume of $2 \mathrm{~mL}$ with a phosphate buffer solution $(\mathrm{pH}=7.4)$. The tissues were then homogenized in an icy environment. After that, the tissues were centrifuged at $1000 \mathrm{rpm}$ for $15 \mathrm{~min}$ at a temperature of $4^{\circ} \mathrm{C}$. The supernatant was used as the sample for the analysis. The protein concentration of the supernatant was measured with the method described by Bradford [17].

\section{MDA analysis}

According to the method defined by Ohkawa et al. MDA forms a pink complex with thiobarbituric acid (TBA) at $95^{\circ} \mathrm{C}$, which can be measured using spectrophotometer at a wavelength of $532 \mathrm{~nm}$ [18]. The Standard curve was obtained by using 1,1,3,3-tetramethoxypropane (Sigma-Aldrich, Germany).

\section{NO analysis}

NO levels of the tissues were measured as the total nitrite + nitrate levels with the use of the Griess reagent in a two-step process, as previously described [19]. The Standard curve was obtained by using potassium nitrate (Merck, Germany).

\section{tGSH analysis}

According to the method defined by Sedlak et al., DTNB (5,5'dithiobis [2-nitrobenzoic acid]) disulfide is chromogenic in the medium, and reduced easily by sulfhydryl groups. The yellow color produced during the reduction is measured by spectrophotometer at $412 \mathrm{~nm}$ [20]. The Standard curve was obtained by using oxidized glutathione (GSSG, Sigma-Aldrich, Germany). 


\section{GST activity}

GST activity was determined using Habig and Jakoby method [21].

\section{GPO activity}

GPO activity was determined using the method described by Lawrence and Burk [22].

\section{CAT activity}

Activity is based on the measurement of decrease occurred in absorbance when $\mathrm{H}_{2} \mathrm{O}_{2}$ is converted to $\mathrm{H} 2 \mathrm{O}$ through CAT, at $240 \mathrm{~nm}$. CAT activity was determined using the method described by Aebi [23].

\section{Gene expression of $I L-1 \beta$ and TNF- $\alpha$}

RNA was isolated from the homogenized jejunum tissue samples using the Roche Magna Pure Compact LC device (Meinheim, Germany) with MagNA Pure LC RNA Kit (Roche Diagnostics). The quantity and quality of the isolated RNA was assessed with a nucleic acid measurement device (Maestro, Nano). cDNA was synthesized from the isolated RNA samples using the Transcriptor First Strand cDNA Synthesis Kit (Roche Diagnostics) according to user manuel of manufacturer. Quantitative gene expression was evaluated by real-time polymerase chain reaction. PCR reactions were recorded in a final volume of $20 \mu \mathrm{l}: 5 \mu \mathrm{l}$ cDNA, $3 \mu \mathrm{l}$ distilled water, $10 \mu \mathrm{l}$ LightCycler 480 Probes Master (Roche Diagnostics), and $2 \mu \mathrm{l}$ primer-probe set (Real-Time Ready single assay, Roche). Cycle conditions of the relative quantitative PCR were preincubation at $95^{\circ} \mathrm{C}$ for $10 \mathrm{~min}$, followed by 45 amplification cycles of $95^{\circ} \mathrm{C}$ for $10 \mathrm{~s}, 6^{\circ} \mathrm{C}$ for $30 \mathrm{~s}, 72^{\circ} \mathrm{C}$ for $1 \mathrm{~s}$, followed by cooling at $40^{\circ} \mathrm{C}$ for $30 \mathrm{~s}$.

\section{Serum IL-1 $\beta$ and TNF- $\alpha$ analysis}

Serum IL-1 $\beta$ and TNF- $\alpha$ concentrations were measured using the rat-specific sandwich enzyme-linked immunosorbent assay kits (eBiosience, Austria).

\section{Histopathological examination}

Jejunal tissues removed from the rats were fixed in $10 \%$ formalin solution for $24 \mathrm{~h}$. Sections of 4 micron thickness were obtained from the paraffin blocks that were obtained following the routine tissue monitoring and stained with hematoxylin \& eosin. All sections were evaluated under light microscopy (Olympus BX 52, Tokyo, Japan) by a pathologist who was not aware of the treatment protocols.

\section{Statistical analysis}

Statistical analyses were carried out using the Statistical Package for Social Sciences, Windows version 18.0 (SPSS, Chicago, IL, USA). Descriptive statistics for each variable were determined. Normality of the data distribution was assessed with the Kolmogorov-Smirnov test. Results for continuous variables were demonstrated as mean \pm standard deviation of the mean (mean $\pm \mathrm{SD}$ ). Significance of differences between the groups was determined using one-way ANOVA test followed by Fisher's post-hoc LSD (least significant differences) analysis. A p value less than 0.05 was considered significant.

\section{Results}

\section{Results of processing}

None of the animals that received cisplatin and were treated with HR for seven days died. However, weight loss and a decrease in movement were more marked in the cisplatin group than in the animals that were administered HR.

\section{Biochemical results}

The tissues were immediately taken for the chemical procedures following removal from all the animal groups. As shown in Figure 1A, cisplatin significantly increased the amount of MDA in the rat jejunum tissue compared to the control group $(\mathrm{p}<0.001)$. HR at doses of 25 and $50 \mathrm{mg} / \mathrm{kg}$ also significantly inhibited the increase of MDA by cisplatin in the jejunal tissue $(p<0.001)$. There was a significant difference in the MDA levels between the HR25+Cis and control groups, while the levels of MDA were almost the same between $\mathrm{HR} 50+\mathrm{C}$ is and control groups. Again, cisplatin significantly decreased the levels of tGSH and GST in the jejunal tissue compared to the HR25+Cis, HR50+Cis, and control groups $(\mathrm{p}<0.001$; Figures $1 \mathrm{~B}$ and $1 \mathrm{C})$. The levels of tGSH and GST slightly decreased in the HR25+Cis group. However, levels of tGSH and GST were not affected by cisplatin in the jejunal tissue of the HR50+Cis group (Figures 1B and 1C).
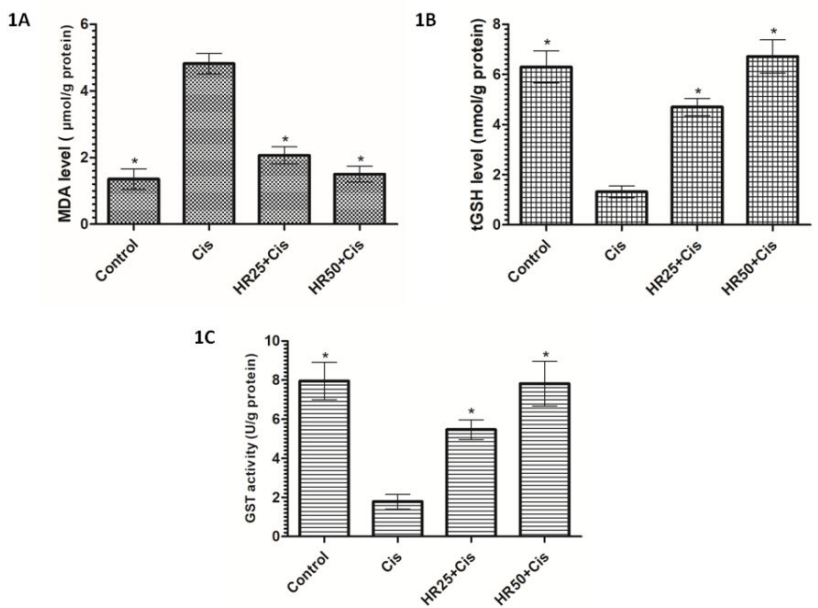

Figure 1. The effects of HR on MDA. 1A) tGSH; 1B) levels and GST; 1C) Activity in the jejunum tissues of rats given cisplatin. Bars are mean $\pm S D$. Cis group is compared with the other groups. ${ }^{*} p<0.001$ (Each bar includes results of six animals).

Cisplatin also inhibited GPO and CAT activities in the jejunal tissue. At a dose of $50 \mathrm{mg} / \mathrm{kg}$, HR was better able to prevent a decrease in GPO and CAT activities than it was at $25 \mathrm{mg} / \mathrm{kg}$ (Figures 2A and 2B). In addition, HR significantly inhibited the decrease of CAT levels by cisplatin in the jejunal tissue $(p<0.001$; Figure 2B). Cisplatin administration caused a significant increase in the levels of NO in the jejunal tissue 
compared to the control group $(\mathrm{p}<0.001$; Figure $2 \mathrm{C})$. At the same time, the amount of NO did not increase in the jejunal tissues of the rats given HR at doses of 25 and $50 \mathrm{mg} / \mathrm{kg}$, despite concurrent cisplatin administration (Figure 2C).

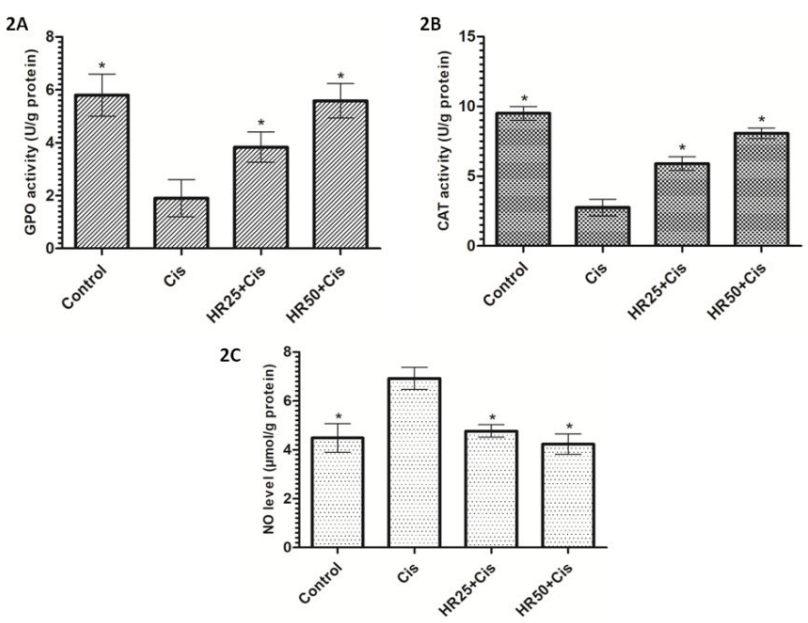

Figure 2. The effects of HR on GPO. 2A), CAT; 2B) activities and $N O ; 2 C)$ levels in the jejunum tissues of rats given cisplatin. Bars are mean $\pm S D$. Cis group is compared with the other groups. ${ }^{*} p<0.001$. (Each bar includes results of six animals).

IL-1 $\beta$ and TNF- $\alpha$ gene expressions were found to be higher in the jejunal tissue of the rats that received cisplatin, compared to the HR25+Cis, HR50+Cis, and control rat groups $(\mathrm{p}<0.001$; Figure 3A). The differences between the HR50+Cis and control rats in terms of these parameters were not statistically significant $(p>0.05)$, but the differences between the HR25+Cis and control groups were found to be highly significant $(\mathrm{p}<0.001$; Figure $3 \mathrm{~A})$. Cisplatin caused a significant increase in the levels of IL- $1 \beta$ and TNF- $\alpha$ (Figure 3B).HR was better at preventing an increase in the serum levels of IL-1 $\beta$ and TNF- $\alpha$ in animals at a $50 \mathrm{mg} / \mathrm{kg}$ dose compared to a 25 $\mathrm{mg} / \mathrm{kg}$ dose (Figure 3B).

\section{Histopathological findings}

Histopathological findings in six different sections taken from each jejunum tissue were found to be almost the same within each group. A normal histopathological view of jejunum tissue from the control group is shown in Figure 4A (H\&E 200X). Histopathologically, we found hemorrhage (green arrow) in the lamina propria and mononuclear inflammatory cell infiltration accompanied by eosinophils (blue arrow) and dilated congested capillary vessel proliferation concentrated in the submucosa (yellow arrow, H\&E 200X) in the jejunum tissue of the Cis group (Figure 4B). Figure 4C illustrates smoothening of the jejunum villus surface epithelium of the Cis rat group (red arrow) and mixed inflammatory cell infiltration (yellow arrow) in the lamina propria (H\&E 200X). Figure 4D shows sporadic flattening (arrow) in the jejunal villi and dilated congested capillaries (star) in the serosa in the HR25+Cis group (HE\&40). In Figure 4E, the protected villus epithelium structure (blue arrow) and mild dilated congested capillary vessel structure are visible in the $\mathrm{HR} 50+\mathrm{Cis}$ rat groups $(\mathrm{H} \& \mathrm{E}$ 200X).

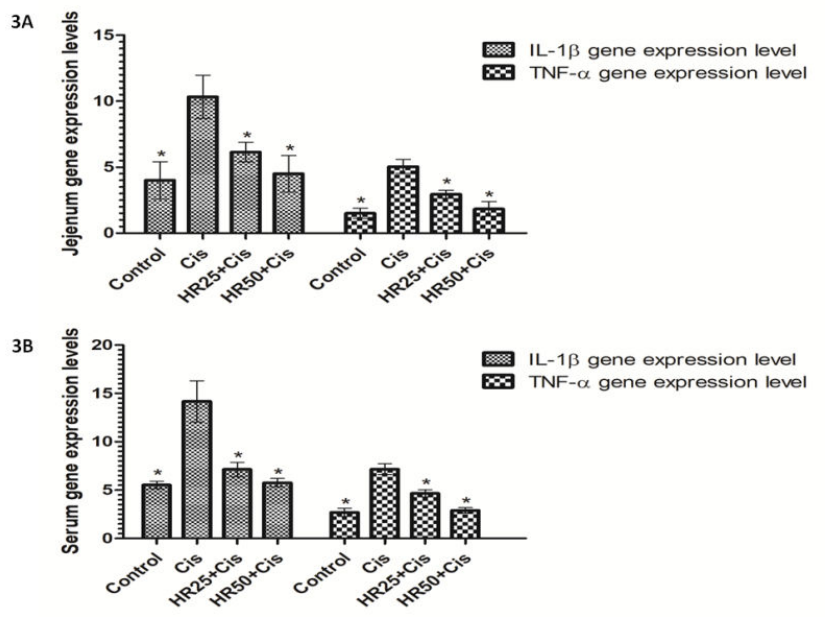

Figure 3. The effects of $H R$ on $I L-1 \beta$, and $T N F-\alpha$ gene expression in the jejunum tissues. 3A) Serum levels of $I L-1 \beta$ and $T N F-\alpha$; 3B) Of rats given cisplatin. Bars are mean $\pm S D$. Cis group is compared with the other groups. ${ }^{*}<0.001$ (Each bar includes results of six animals).

There were no pathological findings in the rat jejunum tissue of the control group. Most pathological findings were recorded in the Cis group. HR at a dose of $50 \mathrm{mg} / \mathrm{kg}$ was better able to prevent tissue damage in the jejunum induced by cisplatin compared to $\mathrm{HR}$ at a dose of $25 \mathrm{mg} / \mathrm{kg}$.

\section{Discussion}

In this study, the effects of HR on experimental jejunum mucositis induced by cisplatin in rats were investigated. Our experimental data demonstrated that, levels of MDA, an oxidant parameter, and proinflammatory cytokines, such as IL- $1 \beta$ and TNF- $\alpha$, were higher in the Cis group, which developed severe hyperemia and ulcers. Additionally, the levels of non-enzymatic and enzymatic antioxidant parameters including tGSH, GST, GPO, and CAT were lower in the Cis group. MDA is an end product of lipid per oxidation. Lipid per oxidation events in the cells are recognized as an indicator of oxidative stress [8]. It has been emphasized that cisplatin increases the amount of MDA through lipid per oxidation, leading to oxidative stress [24]. Increased production of superoxide anions, hydrogen peroxide, and hydroxyl radicals by cisplatin are considered responsible for the initiation of lipid per oxidation and subsequent MDA formation [25]. Our experimental results indicated that cisplatin led to oxidative stress in the jejunal mucosal tissue of rats. Bodiga et al. previously reported that cisplatin causes ileum mucositis due to oxidative stress [8]. Sonis et al. concluded that the increase in ROSs due to oxidative stress leads to ulcers in the mucosa [7]. The oxidant/antioxidant balance is maintained by the superiority of antioxidants in physiological conditions. The change of this balance in favor of oxidants causes oxidative stress [26]. In the current study, the level of tGSH was found to be lower in jejunal tissues with a high level of MDA. Khan et 
al. demonstrated that cisplatin causes damage in the ileal tissue by increasing the levels of MDA and decreasing the levels of tGSH [27]. It has been reported that the severity of oxidative stress is proportionally increased with rising MDA and decreasing tGSH levels [28]. tGSH keeps sulfhydryl groups of molecules reduced, inhibiting their oxidation [29]. Our finding of decreased levels of sulfhydryl groups in the jejunal tissue of animals receiving cisplatin indicates that our results are compatible with the literature [30].

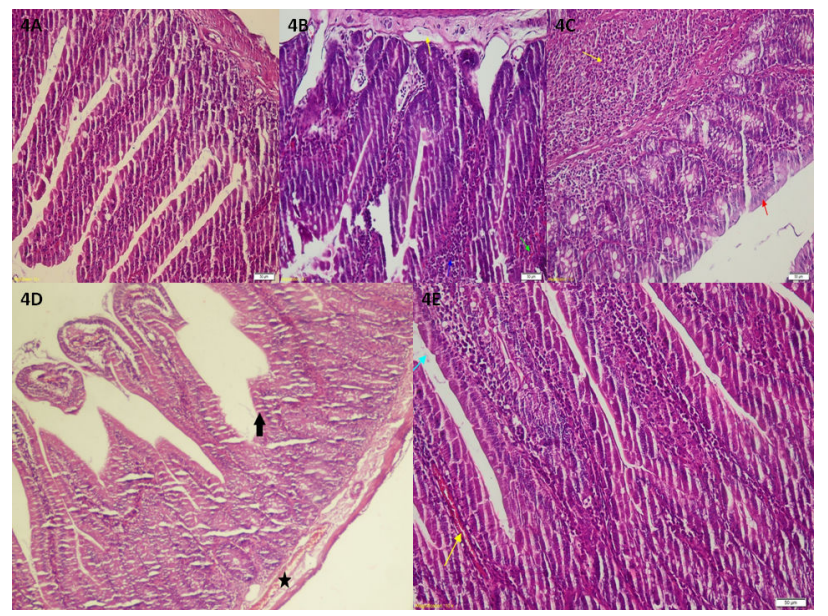

Figure 4. Sections of the jejunum tissue of control. A) Cis; $B \& C)$ HR25+Cis; D) HR50+Cis; E) Groups. A. A normal histopathological view. B. Hemorrhage (green arrow) in the lamina propria and mononuclear inflammatory cell infiltration accompanied by eosinophils (blue arrow) and dilated congested capillary vessel proliferation in the submucosa (yellow arrow). C. Smoothening of the jejunum villus surface epithelium (red arrow) and mixed inflammatory cell infiltration (yellow arrow) in the lamina propria. D. Sporadic flattening (arrow) in the jejunal villi and dilated congested capillaries (star) in the serosa. E. The protected villus epithelium structure (blue arrow) and mild dilated congested capillary vessel.

In the current study, a significant decrease was found in GPO activity in the jejunal tissue of animals that received cisplatin. As previously reported, decreased GPO activity causes a drop in reduced glutathione and a rise in oxidized glutathione (GSSG), leading to a decrease in the GSH-to-GSSG ratio [31]. Naqshbandi et al. reported that cisplatin significantly reduced GPO activity in the jejunal tissue compared to healthy tissues [30]. In addition to these antioxidant parameters, cisplatin was also found to significantly suppress CAT activity. CAT is considered an enzymatic antioxidant; this substance inhibits the formation of toxic hydroxyl radicals by catalyzing the decomposition of hydrogen peroxide $\left(\mathrm{H}_{2} \mathrm{O}_{2}\right)$ to oxygen and water [32,33]. It has been reported that CAT activity is decreased in tissue damage induced by cisplatin [30]. Again, in our study, the levels of NO were significantly elevated in the jejunal tissue of cisplatin-administered rats. The rise of NO in the tissue induced by cisplatin is also supported by previous studies [34]. In one such study, Vera et al. reported that cisplatin increased NO synthesis in gastrointestinal tissue [35].

In the present study, IL- $1 \beta$ and TNF- $\alpha$ levels were also found to be higher in the jejunal tissue of the cisplatin-administered group that displayed MDA and NO levels that were greater than those of the control group. In the literature, IL-1 $\beta$ and TNF- $\alpha$ are considered proinflammatory cytokines. IL- $1 \beta$ has been reported to lead to leukocyte infiltration, inflammation, and apoptosis, while TNF- $\alpha$ has been suggested to have inflammatory activity in addition to a cytotoxic effect [36-38]. IL-1 $\beta$ and TNF- $\alpha$ reportedly increase oxidative stress [37]. No studies in the literature have concluded that cisplatin induces IL- $1 \beta$ and TNF- $\alpha$ in jejunal tissue. However, it has been argued that these cytokines play an important role in the nephrotoxic effect of cisplatin [39]. We investigated the protective effect of HR against cisplatin mucositis and found that HR was better at preventing a change in the oxidant/antioxidant balance in favor of oxidants at a $50-\mathrm{mg} / \mathrm{kg}$ dose than at a $25 \mathrm{mg} / \mathrm{kg}$ one. In addition, $50 \mathrm{mg} / \mathrm{kg}$ of HR better prevented an increase in the levels of IL- $1 \beta$ and TNF- $\alpha$ induced by cisplatin. The protective effects of $\mathrm{HR}$ on the jejunal tissue could result from the antioxidant activities of its contents, including carotenoid $(\alpha, \beta$, $\gamma$ ), vitamin $\mathrm{C}$, tocopherols (vitamin E), linoleic acid, $\alpha$ linolenic acid, palmitoleic acid. Karimi $\mathrm{E}$ et al. reported that plant extract containing linoleic, palmitoleic, and fatty acid has antioxidant properties [40]. It has been suggested that antioxidant activity may decrease the effects of chemotherapy agents. However, the opposite has been demonstrated [41]; they increase the antitumoral effects of chemotherapy $[42,43]$. Chemotherapy increases the amount of lipid per oxidation products and decreases plasma levels of antioxidants, such as vitamins $\mathrm{A}, \mathrm{E}$, and $\mathrm{C}$ [41]. Therefore, in cancer chemotherapy, vitamins $E$ and $C$ and $\beta$-carotenes are needed [44]. Vitamin $A$ is found as a form of carotene in the plants; $\beta$-carotene and $\alpha$ tocopherol are the most commonly studied vitamins for the treatment of cancer due to their antioxidant features $[44,45]$. Protective effects of $\beta$-carotene against mucositis formation have been reported in cancer patients receiving chemotherapy, and it was shown that side effects were minimized and the survival time was prolonged with concurrent $\beta$-carotene administration [44].

In this study; marked hemorrhage, mononuclear inflammatory cell infiltration, dilated capillary vessel proliferation, and smoothening of the villus surface epithelium were observed in the jejunum of the Cis group, which had high oxidant and low antioxidant parameters. Only sporadic flattening in the villi and dilated congested capillaries were seen in the jejunal tissue of the HR25+Cis group. Mildly dilated congested capillaries were also found in the jejunum of the HR50+Cis group. Moghadam et al. histopathologically showed that hemorrhage developed in the oxidative bowel damage induced by the chemotherapy [46]. In addition, it has been reported that erythema and atrophy in the epithelium arises due to inflammatory cell infiltration and capillary vessel proliferation in mucositis $[46,47]$. Oxidant levels are high and antioxidant levels are low in the bowel tissue, and any smoothening was monitored in the villus epithelium [46]. In our study, the smoothening that was observed in the villus epithelium reflects the atrophy of epithelial cells. Serious atrophy in the villus epithelium caused by cisplatin was also reported by Bodiga et al. [8]. A protective effect of HR on the bowel tissue may result from the vitamins 
it contains, which have antioxidant activity. As a result, plasma levels of vitamins were markedly decreased in cases of oxidative damage of the bowel tissue caused by cisplatin [48]

A single dose of $6-\mathrm{mg} / \mathrm{kg}$ cisplatin led to oxidative damage in the rat jejunal tissue, which is called mucositis. HR at 25 and $50 \mathrm{mg}$ doses protected the jejunal tissue against oxidative stress induced by cisplatin. Literature data suggests that the protective effect of HR on the oxidative damage of intestinal tissue caused by cisplatin is due to the total effect of $\beta$ carotene, fatty acids and vitamins in the content. However, HR was more effective at a dose of $50 \mathrm{mg} / \mathrm{kg}$. These findings suggest that HR may be useful in the prophylaxis of intestinal damage due to cisplatin chemotherapy in the clinic.

\section{Acknowledgement}

This research was supported by the Erzincan University Scientific Research Projects Department (SAGA-080715-0160).

\section{References}

1. Rosenberg B. Platinum complexes for the treatment of cancer. Cisplatin-chemistry and biochemistry of a leading anticancer drug. Zurich: Verlag Helvetica Chimica Acta 1999.

2. Jamal A, Murray T, Samuels A, Ghafoor A, Ward E, Thun M. Cancer statistics, 2003. Ca Cancer J Clin 2003; 53: 5-26.

3. Duncan M, Grant G. Review article: oral and intestinal mucositis-causes and possible treatments. Aliment Pharm Ther 2003; 18: 853-874.

4. Niscola P, Romani C, Cupelli L, Scaramucci L, Tendas A, Dentamaro T. Mucositis in patients with hematologic malignancies: an overview. Haematol-Hematol J 2007; 92: 222-231.

5. Lalla RV, Peterson DE. Treatment of mucositis, including new medications. Cancer J 2006; 12: 348-354.

6. Dogan Z, Ergul B, Sarikaya M, Filik L, Gonultas MA, Hucumenoglu S. The protective effect of Echinacea spp. (Echinacea angustifolia and Echinacea purpurea) in a rat colitis model induced by acetic acid. Pak J Pharm Sci 2014; 27: 1827-1835.

7. Sonis ST, Elting LS, Keefe D, Peterson DE, Schubert M, Hauer-Jensen M. Perspectives on cancer therapy-induced mucosal injury - Pathogenesis, measurement, epidemiology, and consequences for patients. Cancer 2004; 100: 1995-2025.

8. Bodiga VL, Bodiga S, Surampudi S, Boindala S, Putcha U, Nagalla B. Effect of vitamin supplementation on cisplatininduced intestinal epithelial cell apoptosis in Wistar/NIN rats. Nutrition 2012; 28: 572-580.

9. Keefe DM, Schubert MM, Elting LS, Sonis ST, Epstein JB, Raber-Durlacher JE. Updated clinical practice guidelines for the prevention and treatment of mucositis. Cancer 2007; 109: 820-831.
10. Guliyev VB, Gul M, Yildirim A. Hippophae rhamnoides L.: chromatographic methods to determine chemical composition, use in traditional medicine and pharmacological effects. J Chromatogr B 2004; 812: 291-307.

11. Suleyman H, Gumustekin K, Taysi S, Keles S, Oztasan N, Aktas O. Beneficial effects of Hippophae rhamnoides L. on nicotine induced oxidative stress in rat blood compared with vitamin E. Biol Pharmaceut Bull 2002; 25: 1133-1136.

12. Süleyman H, Demirezer L, Büyükokuroglu M, Akcay M, Gepdiremen A, Banoglu Z. Antiulcerogenic effect of Hippophae rhamnoides L. Phytother Res 2001; 15: 625-627.

13. Andersson SC, Rumpunen K, Johansson E, Olsson ME. Tocopherols and tocotrienols in sea buckthorn (Hippophae rhamnoides L.) berries during ripening. J Agr Food Chem 2008; 56: 6701-6706.

14. Yang B, Kalimo KO, Mattila LM, Kallio SE, Katajisto JK, Peltola OJ. Effects of dietary supplementation with sea buckthorn (Hippophae rhamnoides) seed and pulp oils on atopic dermatitis. J Nutri Biochem 1999; 10: 622-630.

15. Yilmaz I, Demiryilmaz I, Sener E, Cetin N, Ucuncu Y, Altuner D. The Effect of Hippophae rhamnoides extract on oxidative damage on rat's gastric tissue depending on coimplementation of methotrexate and indomethacin. Lat Am J Pharm 2014; 33: 453-458.

16. Shahid F, Farooqui Z, Abidi S, Parwez I, Khan F. Oral administration of thymoquinone mitigates the effect of cisplatin on brush border membrane enzymes, energy metabolism and antioxidant system in rat intestine. Biomed Pharmacother 2017; 94: 1111.

17. Bradford MM. A rapid and sensitive method for the quantitation of microgram quantities of protein utilizing the principle of protein-dye binding. Anal Biochem 1976; 72: 248-254.

18. Ohkawa H, Ohishi N, Yagi K. Assay for lipid peroxides in animal tissues by thiobarbituric acid reaction. Anal Biochem 1979; 95: 351-358.

19. Moshage H, Kok B, Huizenga JR, Jansen P. Nitrite and nitrate determinations in plasma: a critical evaluation. Clin Chem 1995; 41: 892-896.

20. Sedlak J, Lindsay RH. Estimation of total, protein-bound, and nonprotein sulfhydryl groups in tissue with Ellman's reagent. Anal Biochem 1968; 25: 192-205.

21. Habig WH, Jakoby WB. Assays for differentiation of glutathione S-Transferases. Method Enzymol 1981; 77: 398-405.

22. Lawrence RA, Burk RF. Glutathione peroxidase activity in selenium-deficient rat liver. Biochem Biophysical Res Commun 1976; 71: 952-958.

23. Aebi H. Catalase Invitro. Method Enzymol 1984; 105: 121-126.

24. Chang BJ, Nishikawa M, Sato E, Utsumi K, Inoue M. LCarnitine inhibits cisplatin-induced injury of the kidney and small intestine. Arch Biochem Biophys 2002; 405: 55-64. 
25. Sun Y. Free radicals, antioxidant enzymes, and carcinogenesis. Free Radical Biol Med 1990; 8: 583-599.

26. Kisaoglu A, Borekci B, Yapca OE, Bilen H, Suleyman H. Tissue damage and oxidant/antioxidant balance. Eurasian J Med 2013; 45: 47.

27. Khan R, Khan AQ, Qamar W, Lateef A, Ali F, Rehman MU. Chrysin abrogates cisplatin-induced oxidative stress, p53 expression, goblet cell disintegration and apoptotic responses in the jejunum of Wistar rats. Br $\mathrm{J}$ Nutrition 2012; 108: 1574-1585.

28. Polat B, Suleyman H, Alp HH. Adaptation of rat gastric tissue against indomethacin toxicity. Chemico Biol Interact 2010; 186: 82-89.

29. Urso ML, Clarkson PM. Oxidative stress, exercise, and antioxidant supplementation. Toxicology 2003; 189: 41-54.

30. Naqshbandi A, Rizwan S, Khan MW, Khan F. Dietary flaxseed oil supplementation ameliorates the effect of cisplatin on brush border membrane enzymes and antioxidant system in rat intestine. Hum Exp Toxicol 2013; 32: 385-394.

31. Melchiorri D, Sewerynek E, Reiter RJ, Ortiz GG, Poeggeler B, Nistico G. Suppressive effect of melatonin administration on ethanol-induced gastroduodenal injury in rats in vivo. Br J Pharmacol 1997; 121: 264-270.

32. Reilly PM, Schiller HJ, Bulkley GB. Pharmacologic approach to tissue injury mediated by free radicals and other reactive oxygen metabolites. Am J Surg 1991; 161: 488-503.

33. Huang R, Zhong $\mathrm{T}$, Wu $\mathrm{H}$. Quercetin protects against lipopolysaccharide-induced acute lung injury in rats through suppression of inflammation and oxidative stress. Arch Med Sci 2015; 11: 427.

34. Borekci B, Yapca OE, Turan MI, Gul MA, Isaoglu U. Prevention of ovarian oxidative stress - related infertility associated with cisplatin in rats with thiamine pyrophosphate. Lat Am J Pharm 2013; 32: 512-517.

35. Vera G, Castillo M, Cabezos P, Chiarlone A, Martín M, Gori A. Enteric neuropathy evoked by repeated cisplatin in the rat. Neurogastroenterol Motility 2011; 23: 370.

36. Dinarello CA. Proinflammatory cytokines. Chest 2000; 118: 503-508.

37. Semenzato G. Tumour necrosis factor: a cytokine with multiple biological activities. BrJ Cancer 1990; 61: 354.

38. Khanavi M, Sabbagh-Bani-Azad M, Abdolghaffari AH, Vazirian M, Isazadeh I, Rezvanfar MA. On the benefit of galls of Quercus brantii Lindl. in murine colitis: the role of free gallic acid. Arch Med Sci 2014; 10: 1225-1234.

39. Ramesh G, Reeves WB. TNF- $\alpha$ mediates chemokine and cytokine expression and renal injury in cisplatin nephrotoxicity. J Clin Invest 2002; 110: 835.
40. Karimi E, Jaafar HZE, Ghasemzadeh A, Ebrahimi M. Fatty acid composition, antioxidant and antibacterial properties of the microwave aqueous extract of three varieties of Labisia pumila Benth. Biol Res 2015.

41. Simone II CB, Simone NL, Simone V, Simone CB. Antioxidants and other nutrients do not interfere with chemotherapy or radiation therapy and can increase kill and increase survival, part 1. Alternat Ther Health Med 2007; 13: 22 .

42. Block KI, Koch AC, Mead MN, Tothy PK, Newman RA, Gyllenhaal C. Impact of antioxidant supplementation on chemotherapeutic efficacy: A systematic review of the evidence from randomized controlled trials. Cancer Treat Rev 2007; 33: 407-418.

43. D'Andrea GM. Use of antioxidants during chemotherapy and radiotherapy should be avoided. Ca-Cancer J Clin 2005; 55: 319-321.

44. Mills E. The modifying effect of beta-carotene on radiation and chemotherapy induced oral mucositis. $\mathrm{Br} \mathrm{J}$ Cancer 1988; 57: 416.

45. Bairati I, Meyer F, Gelinas M, Fortin A, Nabid A, Brochet F. A randomized trial of antioxidant vitamins to prevent second primary cancers in head and neck cancer patients. J Natl Cancer I 2005; 97: 481-488.

46. Moghadam AR, Mohajeri D, Namvaran-Abbas-Abad A, Manafi H, Shahi D, Mazani M. Protective effect of turmeric extract on ethotrexate-induced intestinal damage and oxidative stress. Chinese J Nat Med 2013; 11: 477-483.

47. Sonis S. Mucositis as a biological process: a new hypothesis for the development of chemotherapy-induced stomatotoxicity. Oral Oncol 1998; 34: 39-43.

48. Vijayalakshmi B, Sesikeran B, Udaykumar P, Kalyanasundaram S, Raghunath M. Chronic low vitamin intake potentiates cisplatin-induced intestinal epithelial cell apoptosis in WNIN rats. World J Gastroenterol 2006; 12: 1078.

\section{*Correspondence to}

Nihal Cetin

Department of Pharmacology

Faculty of Medicine

Selcuk University

Turkey 